\title{
Mitral Valve Insufficiency
}

National Cancer Institute

\section{Source}

National Cancer Institute. Mitral Valve Insufficiency. NCI Thesaurus. Code C50888.

Dysfunction of the mitral valve characterized by incomplete valve closure. 